\title{
First Records Species of Hottentotta Genus (Scorpiones:Buthidae) from Kerman Province, Southeast of Iran
}

\author{
M. Salari ${ }^{1, *}$ and M. Sampour ${ }^{2}$ \\ ${ }^{1,2}$ Department of Biology, Faculty of sciences, Lorestan University \\ Khoramabad, Iran \\ "Corresponding author's email: mmsal01977 [AT] yahoo.com
}

\begin{abstract}
Investigations indicated that the scorpions are scattered in all parts of Iran. Few researches have been carried out to identify and study morphology of the scorpions of Iran. In the present investigations, several species of scorpions from Kerman Province (Iran) have been identified. The scorpions usually live under the stones. To obtain the scorpions, heavy materials including stones, clod and so on, were moved by crow bar and woods. The specimens were captured with a tongs. To study the morphological characters and identify the scorpions, Olympus Lica 2000 stereo microscope and key identify to scorpions, were used. In the present research a species of scorpions belonged to Hottentotta genus and Buthidae family, is reported for the first time from Kerman Province (Iran). This species is called Hottentotta schach and has been collected from Manoujan area, situated in the south and southwest of Kerman Province. The H. schach is a rare species, it is shaggy and some parts of it'sbody are dark. This species lives in height over 1000 meter and also is found in mountainous areas. Beside of this species, 6 other species called: Compsobuthus matthiesseni,Androctonus crassicauda, Odontobuthus doriae, Mesobuthus eupeus, Sassanidotus gracilis, Orthochirus farzanpayi, from this family, are found in the mentioned area. In taxonomy, the scorpions are order belonging to arachnida class, phylum arthropoda, super phylum invertebrate sub kingdom of metazoan and kingdom of animal. The weather in south of Kerman Province is warm and relatively humid.
\end{abstract}

Keywords--- Scorpions, Buthidae, Hottentotta schach, Manoujan, Kerman Province, Iran

\section{INTRODUCTION}

The scorpions are order belonging to class arachnida, phylum arthropoda, super phylum invertebrate sub kingdom of metazoan and kingdom of animals. The first study of Iranian scorpions, performed by Olivier (1807), identified black scorpion Crassicauda in Kashan. Although it has been carried out a long time ago, due to various climate, broadness of the country and lack of studying on some areas of Iran, to complete the scorpions fauna of Iran.

This investigation was carried out on three towns, including Manoujan, Qaleh ganj and Roodbar, situated in the south and southwest of Kerman Province, where is situated in the southeast of Iran. The exact areas of these regions are 4437,10235 and 6296 square kilometers respectively. The average rainfall in Manoujan is 209 mm annually, while the minimum average temperature throughout the year is $19.2^{\circ} \mathrm{C}$, and the maximum average is $33^{\circ} \mathrm{C}$. Regional characteristics of two other cities are almost as same as Manoujan. The area in South of Kerman Province is warm and relatively humid (Jalalifar,et al.,2013). According to Fet (2000), during the last 40 years, the scorpions of Iran have been check-listed several times by some workers. Some papers have published the name of scorpions species as belonging to Buthidae family. These papers are provided by researchers, including Vachon, 1966; Habibi,1971; Farzanpay \& Pertizen, 1974; Perize \& Minosi, 1974; Farzanpay, 1988; Kinzelbech, 1985; and Kovarick,1977. Sampour et al, 2011, studied on morphological and biometrical characters of two genus of scorpions Androctonus and Odontobuthus from Markezy Province of Iran. Morphological studies of sensitive seta of scorpions and distribution of scorpions in Lorestan have been carried out by Sampour (2012). The systematic studies on scorpion of Iran have been carried out by Predini (2000), who distinguished and identified hemiscorpiidae family from Iran. Scorpionidae family was a sub family of scorpionidae, called scorpioninae, then it proceed to a family, that mentioned above. A check list of scorpions throughout Iran and four families, including Buthidae (Koch, 1837), Scorpionidae (Latreille,1802), Hemiscorpioiidae (Pocock, 1893) and Diplocentridae (Karsch, 1880) has been reported by Mirshamsi et al (2011), and also they performed studies on species of Mesobuthus eupeus. They reviewed and studied on sub species of the mentioned species. The species of Hemiscorpius lepturus, H. acanthocercus, and H. enischnochela are reported from Kerman Province by Salari \& Sampour (2017).

Most Hottenttota species have been found in west of Iran. Dehghani et al, (2007) have reported H. saulcyi species from Kerman Province. Hottonttota schach, which is reported for the first time, is reported in this investigation from 
Kerman province. Researchers have reported Hottenttota species from Iran so far as follow: Hottentotta jayakari (Pocock 1895), Hottentotta saulcyi (Simon 1880), Hottentotta schach (Birula 1905), Hottentotta zagrosensis (Kovařík 1997), Hottentotta khoozestanus (Navidpouret al2008), Hottentotta lorestanus (Navidpouret al2010). From genus Androctonus, species Androctonus crassicauda, found in many provinces of Iran and abundant in Kerman province.

In some cases, scorpions are found in pengeonry ants, in few numbers or usually in single. It may be happened, because scorpions use the ants and their larva as food. Scorpions are found in warm and moderate climate. They are active in warm weather. They rest in their husting during the day, and are activated at night, and hunt their prey. The scorpions are insectivorous.

The scorpions of Iran, are originated from Africa, because most of Iran scorpions genus found in Africa (Farzanpay, 1988). But some of them, including genera Razianus and Mesobuthus, originated from Iran. Three types of sensitive hair (seta) are found on the body of scorpions (Sampour, 2012) Scorpions possess two middle eyes on middle dorsal surface of carapace and lateral eyes. The number of lateral eyes are between 3-5 pairs. They are situated in lateral margin in front of carapace on each side of head. Some of scorpions like Scorpio maurus and Odontobuthus doriae are digger.

\section{MATERIALS AND METHODS}

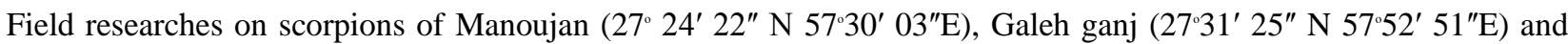

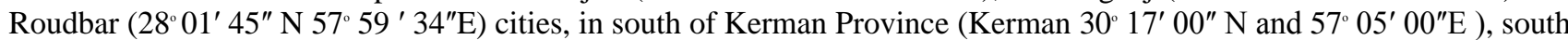
east of Iran (Fig. 1), were carried out during 2013-2014 years. Scorpions were collected from different localities and different parts of the mentioned region, including urban and rural areas. The scorpions were gathered in different seasons of the year. The specimens were collected under stones, stones cleft, clod and holes underground. For moving the stones and other heavy things, wood and crow-bar were used. The samples were captured with a tong. The specimens were fixed in 70\% ethanol, and deposited in the scorpion place in Department of Zoology, Loretan University. Identification of scorpion was performed by using identifying key to scorpions. The morphological studies were carried out under an Olympus Lica 2000 stereo microscope. The photographs were taken by a Nikon camera; Coolpix p6000 model. The sizes were measured with an Electronic Digital Caliper. The environment temperatures were noted by means of a thermometer. All measurements are given in millimeters.

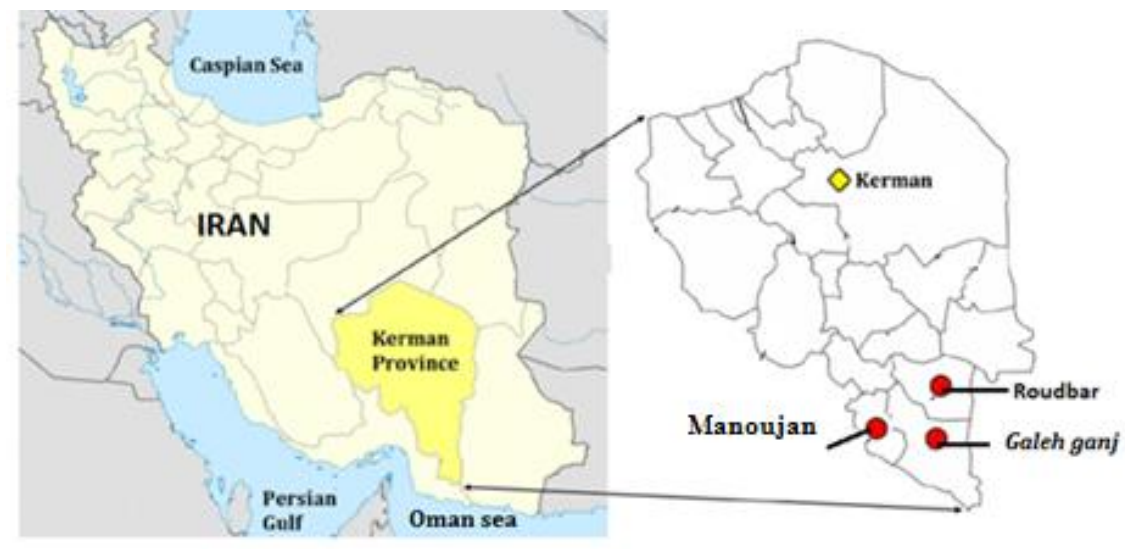

Figure 1: Geographical position of Manoujan, Galehganj and Roudbar cities in the south of Kerman Province.

\section{RESULTS}

In the present investigation seven species from Buthidae family were found in Manoujan, Galeh gange and Roodbar in south of Kerman Province.One species of them, called Hottenttota schach, is reported for the first time from Kerman Province. This species live in hot and relatively wet areas. Some of them are abundant and some are rare. The geographical map of their distribution indicated in Figures 2 and 3.

List of scorpions of south of Kerman Province in the present research, as follow:

Family Buthidae (C. L. Koch, 1837)

Androctonus crassicauda (Olivier, 1807)

Hottentotta schach (Birula, 1905) (first report)

Odontobuthus doriae (Thorell, 1876) 
Compsobuthus matthiesseni (Birula, 1905)

Mesobuthus eupeus (C. L. Koch, 1839)

Sassanidotus gracilis (Birula, 1900)

Orthochirus farzanpayi (Vachon et Farzanpay, 1987)

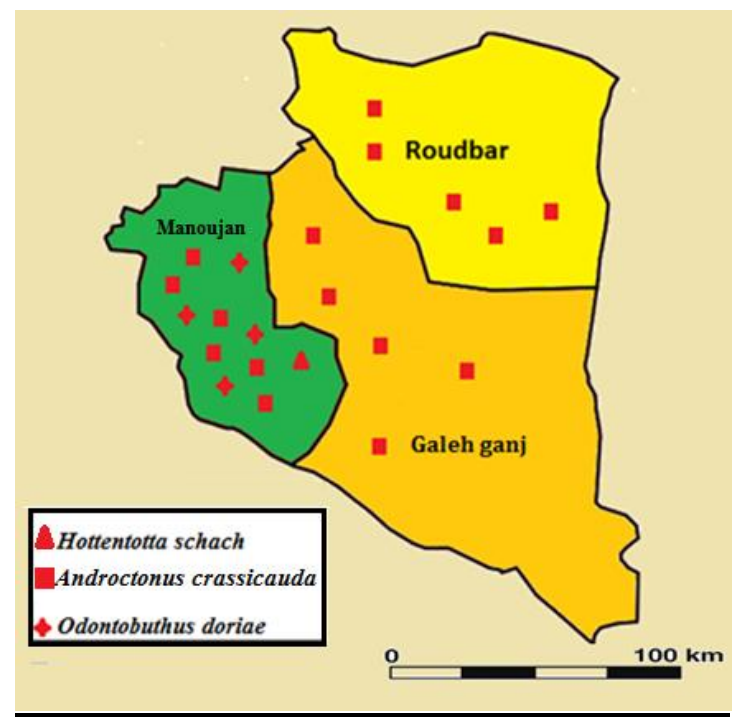

Figure 2: Map of south of Kerman Province, showing distributions of Androctonus crassicauda (Olivier, 1807), Hottentotta schach (Birula, 1905), Odontobuthus doriae (Thorell, 1876) collected in this study.

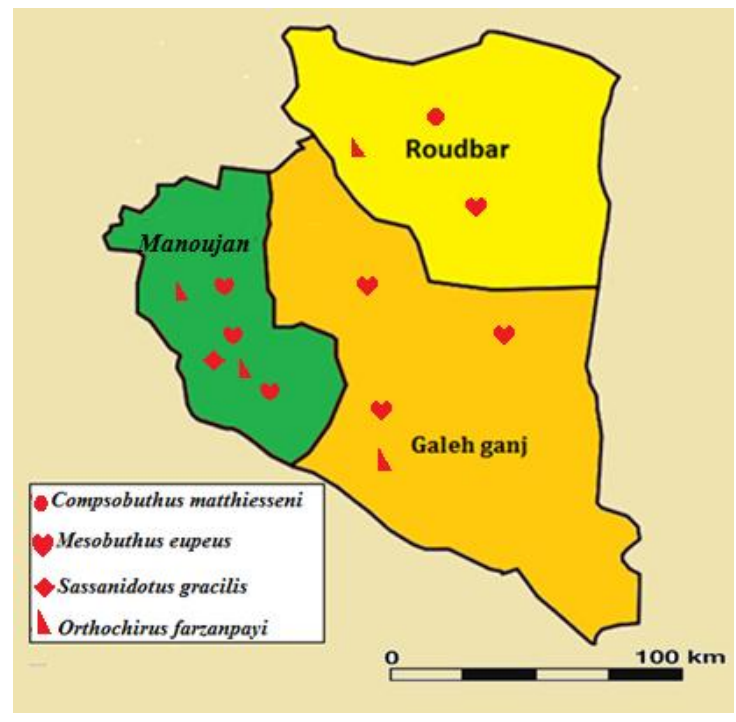

Figure 3: Map of south of Kerman Province showing distributions of Compsobuthus matthiesseni (Birula, 1905), Mesobuthu seupeus (C. L. Koch, 1839), Sassanidot s gracilis (Birula, 1900), Orthochirus farzanpayi (Vachon et Farzanpay, 1987), collected in this study.

Hottentotta schach (Birula, 1905)(Fig.4)

Distribution.Iran. Fars (Kovarik, 2007), Lorestan(Sampour, 2012) and Kerman Provinces (2018) first report.

MATERIAL EXAMINED. Manoujan, Abgel Village.

Explains: The body is yellow, and black. In samples with yellow half infront, carapace, chelicerae and eyes dominance are quite dark. The eye, brow arcs, and also middle eyes are so dominant. There are 3 big lateral eyes in each side of carapace. There are 3 dark tapes on dorsal of mesosoma. Patella (lighter than chelae), telson, fifth segment and the posterior part of forth metasoma segment are ranged from dark brown to dark colors. Mesosoma possesses scattered 
sensory hair and in terminal part of each tergit, sensory hair are in sequence. The seventh segment of mesosoma is yellow, having four dominant carina and abundant sensory chatae. The body of this species is shaggy. Metasoma possesses more sensory hair. The dorsal surface of metasoma is smooth. These hair are compactly found in abdominal and lateral of telson. The length of all segments is more than their width. Chela is stretched, so that the length of movable finger is three times more than the manus length. Chelicera are black and reticular. Hottenttota schach is very rare in south of Kerman Province. This species mainly live in mountainous areas and at the foot of mountains. In the area under studying, it is not seen in rocky desert and gardens. Movable finger in pedipalp possesses 15 rows of granules and having internal and external granules. Also there are 6 external granules in movable finger. Chela is extended, so the length of movable finger is 3 times longer than manus. The chelicerae are black and reticular. The third and fourth legs possesses a tibia spur,and all legs have two tarsusspur. Pectin possesses 26 dents. Biometry of this species indicated in Table 1.

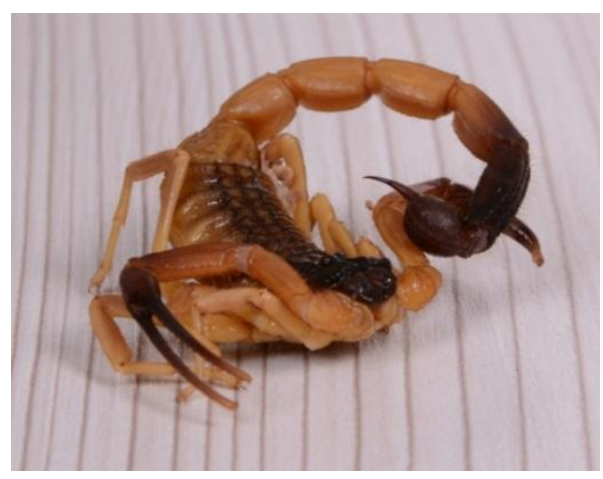

Figure 4: Hottentott aschach

Table 1: Biometrical characters of Hottentotta schach (Measurements are in mm)

\begin{tabular}{|c|c|}
\hline Characters & Female \\
\hline Carapace length & 9 \\
\hline Carapace posterior wide & 10.5 \\
\hline Mesosoma length & 18.3 \\
\hline Metasoma length & 42.3 \\
\hline Pedipalp, femur length /width & $9 / 2.6$ \\
\hline Pedipalp Patella, length / width & $10.5 / 3$ \\
\hline Chela length & 18.8 \\
\hline Manus, length / width / depth & $5 / 3 / 3$ \\
\hline Pedipalp movable finger Length & 14 \\
\hline Pedipalp fixed finger Length & 12.8 \\
\hline Metasoma segment I, length / width/ depth & $6 / 5$ \\
\hline Metasoma segment II , length / width/ depth & $7 / 4.5$ \\
\hline Metasoma segment III, length / width/ depth & $7 / 4.3$ \\
\hline Metasoma segment IV, length / width/ depth & $8.4 / 4 / 15$ \\
\hline Metasoma segment V, length / width / depth & $10 / 4.15$ \\
\hline Vesicle, length / width /depth & $6.2 / 4 / 4.3$ \\
\hline Aculeus length & 4.2 \\
\hline Number of pectnial tooth & 26 \\
\hline Total length & 79.2 \\
\hline
\end{tabular}




\section{Compsobuthus matthiesseni (Birula, 1905)}

Distribution. The species Found in Kerman, Fars, Hamadan, Kermanshah, Azarbaijan, Boshehr, Ilam, Khuzestan, Kordestan, Lorestan, Markazi, Qom (Sissom, \&Fet, 1998; Kovarik, 2003; Akbari, 2007; Mirshamsi et al. 2011) Kohgilouyeh \& Boyer Ahmad, ChaharMahal \& Bakhtiyari, (Pirali-Kheirabadi et al. 2009), provinces of Iran. Iraq, Turkey and Syria (Kovař́k, 1996).

\section{MATERIAL EXAMINED. Roudbar: Kilometr 15 Road of Roudbar- Jiroft.}

Explains: Median-central and median -posterior carina in carapace are separated from each other by small space. These carina made together a line carina. In metasoma $5^{\text {th }}$ and half posterior of $4^{\text {th }}$ segment are black. In tergits of mesosoma each carina possesses a spine like process arose from posterior margin of tergit. Pedipalps possesses very narrow and long chelae. Each of moving and fixed finger of pedipalps possesses 10 oblique rows of granules, but there is no external granules. Their movable finger possesses 5 terminal granules. The pectineal dents in males are 22 .

\section{Orthochirus farzanpayi (Vachon et Farzanpay, 1987)}

Distribution: Iran. Bushehr, Hormozgan, Kerman, and Khuzestan Provinces (Farzanpay, 1987; Kovařík\&Fet,2006; Navidpouret al, 2011).

MATERIAL EXAMINED. Manoujan: Boneg Village, Zeyaratabolfazl village,Nodej Salarabad village, Khosroabad Village, Roudbar: Kilometr 15 Road of Roudbar- Jiroft.

Comment: Metasomal segments $4^{\text {th }}$ and $5^{\text {th }}$ ventrally punctated and without carinae. Colour of mesosoma and metasoma black, telson reddish brown, femur of pedipalp gray. In adults, legs and pedipalps yellow, in juveniles, femur of legs and pedipalps black. The movable finger in pedipalp possesses 8-9 rows of granules with internal and external granules, and also 3 terminal granules. In different samples. The pectin dents are between 20-21. Orthochirus farzanpay, living in warm and dry mountainous areas, specially on mountain feet. In spring, they are found under stone.

\section{DISCUSSION}

South of Kerman Province has different species of scorpions in this province, because of hot weather and suitable conditions. Seven species of scorpions were found from Buthidae family. In the present investigation, the species Hottonttota schach was found in Kerman Province for the first time, species Compsobuthus matthiesseni, and Orthochirus farzanpay are reported for the first time from the Manoujan, Galeh ganj and Roodbar areas, south of Kerman Province. Thes pecies Compsobuthus matthisseni, Sassanidotus gracilis and Hottonttota schach are rare species in the mentioned areas. Some researchers classified genus of Hottentotta to different groups. They changed the name of this genus to Buthus genus previously. More investigations indicated that some species of Buthus genus have some differences from each other. So, some researchers divided the genus Buthus into many genera. Vachon (1949), suggested that genus Buthus, as one of this genera. Furthermore, a long time ago, it had been considered, due to variety climate, width of the country and lack of studying on some areas of Iran, more investigation would be necessaryto complete the scorpions fauna of Iran.

The Hottonttota,species, are distributed from Asia to Africa. 29 species of Hottentotta have been identified in the world. Hottentotta species are found in many parts of Iran, and are important in medicine. 6 species of Hottonttota were found in Iran, including H. jayakari (Pocock 1895), H. saulcyi (Simon 1880), H. schach (Birula 1905), H. zagrosensis (Kovař́́k 1997), H. khoozestanus (Navidpouret al. 2008), H. lorestanu (Navidpouret al.2010), H. jayakari (Pocock 1895).

The H. schach, species, in Iran, was reported from Khuzestan and Fars provinces by Birula in 1905. In H. schach the body is yellow and black. The anterior part of carapace is black ,in metasoma, fifth segment and the posterior part of segments $4^{\text {th }}$, also telson are black. This colour is distributed to dorsal margin. In species $H$. saulcyi, the another species of Hottentotta which has been reported previously, the colour of mesosoma is yellow. In Composobuthus matthiesseni, unlike Mesobuthus eupeus, the middle central and middle dorsal carina are connected to each other, and make a line. In Species Sassanidotus gracilis, the movable finger of pedipalp possesses 3 granules, beneath terminal granule, is different from that of genus Compsobuthus and Mesobuthus, which possesses 4 granules beneath the terminal granule. H. schach, Orthochirus farzanpay, Odentobuthus doriae, found in mountains and foot a mountains areas, while A. crassicauda and $M$. eupeus found almost every where of Iran. In the above mentioned species are harmful, and in some cases fatal. The investigations shows at least 10 people in Manoujan, Ghaleh ganj and Roudbar, died because of scorpions sting between years 2012- 2017. In some species of the genus of Hottentota, the length of body is about $115 \mathrm{~mm}$. The number of lateral eyes 3-4 in each side of carapace. Up to species,the body is covered with chaeta. The number of dents pectin is between 30-40 in male, and between 24 -36 in female. Genus of Hottonttota possesses distinguishes carina. Movable finger in pedipalp, possesses 11-16 rows of granules and 5-7 terminal granules. There are 2 accessory denticles on ventral surface in fixed finger of chelicerae. 


\section{REFERENCES}

[1] Akbari, A.,"Study of scorpion fauna of Iran”, Project Report Publication of RaziVaccine \&Serum Research Institute: no. 96, 2007 (in farsi).

[2] Dehghani, R., Mahdiabadi, sh,m., Kamyabi, F., Haghdoost, A.,Mashayekhi, M., Soltani, H., "Scorpions Fauna of Kerman Province-IRAN". Kerman University of Medical Sciences Vol. 15 No2. Page 171-182, 2007. (in Farsi).

[3] Farzanpay, R.,"Knowing Scorpions”, Teheran Central University Publications, No. 312, Biology 4, 231 pp. 1987, (1366) (in farsi).

[4] Fet, V., Subfamily HemiscorpiinaePocock, 1893 (pp. 428-431). In: Fet, V., SISSOM, D.W.,LOWE, G., And BRAUNWALDER, M. E., Catalogue of the scorpions of the world(1758- 1998). The New York Entomological Society, New York, 2000.

[5] Jalalifar,Z., kalantari, M., Naderi, M., Pordehgan, D., Dahesh, K., Latifkar, M,.Naderi, A., Roholamini, F., “Ostanshenasi Kerman”, ChapVaNashreKetabhayedarseiIran.Text. Book, 2013 (inFarsi).

[6] Kovarik, F.,"First report of Compsobuthusmatthiesseni (Scorpiones:Buthidae) from Turkey”,Prvnízpráva o štíruCompsobuthusmatthiesseni z Turecka.Klapalekiana, 2: 53-55, 1996.

[7] Kovarik, F.,"Eight new species of CompsobuthusVachon, 1949 from Africaand Asia (Scorpiones: Buthidae)",Serket, 8(3): 87-112, 2003.

[8] Kovarik, F."“ A revision of the genus HottentottaBirula, 1908, with descriptions of fournew species (Scorpiones, Buthidae)",Euscorpius, 58: 1-107, 2007.

[9] Mirshamsi, O., Sari, A., and Hosseinie, S., "History of study and checklist of the scorpion. fauna (Arachnida: Scorpiones) of Iran", Progress in Biological Sciences, Vol. 1, No.2, 16-28, 2011.

[10] Navidpour, S., Ezatkhah, M., Kovařík, F., Soleglad, ME., Fet, V.,“ Scorpions of Iran (Arachnida-scorpiones). Part VII.Kerman Province",Euscorpius, 131, 1-32, 2011.

[11] Olivier, GA., "Voyage dansl'EmpireOttoman,l'Egypte et la Perse, fait par ordredugouvernement",pendantles six premières années de la république, Paris, 3,96-98. 1807.

[12] Salari, M., Sampour,M,,"First Two Records of Hemiscorpius species (Scorpiones:Hemiscorpiidae) from Kerman Province, Southeast of Iran”, Asian Journal of Applied Sciences.Volume 05 -Issue 01, 101-108,2017.

[13] Sampour, M,,Aslanfaal,S.,Shayestehfar,AR.,Bolandian,A and Mohamadzadeh,S., "Morphological Studies on two Genus of ScorpionsAndroctonus and Odontobuthus from Markezy Province",J.Exp.Zool.India. Vol.14, No.1:349$352,2011$.

[14] Sampour, M,“ Morphological studies of Sensitive Seta of Scorpions and Distributionscorpions (Arachnidascorpiones) in Lorestsn, Iran”, J.Eap.zool. India Vol.15,No.2,pp.413-419,2012.

[15] Sissom, W,D.,\&Fet, V.,"Redescription of Compsobuthusmatthiesseni (Scorpiones, Buthidae) from southwestern Asia”, Journal of Arachnology, 26:1-8,1998.

[16] Pirali-Kheirabadi, K., Navidpour. S., Fet. V., Kovařík, F., Soleglad, M,E.,'Scorpiones of Iran (Arachnida, Scorpions). Part V. ChaharMahal\&Bakhtiyari Province”,Euscorpius, No. 78,2009. 